\title{
MULTIMEDIA AS AN INCENTIVE FOR INTERNAL MOTIVATION AND USE OF COMPUTERS IN SPORTS
}

Kioumourtzoglou, J;;

Zetou E.;

Giannousi M.;

Antoniou, P.;

Michalopoulou, $\mathrm{M}$.

Democritus University of Thrace,

School of Physical Education and Sport Sciences,

Greece

\begin{abstract}
:
The purpose of this study was to present the appropriateness of digital educational material and to explore multimedia usability and the importance of using them in developing the motivation of participants in learning sports skills. The participants were 63 beginner female volleyball athletes, aged 10-12 years $(\mathrm{MO}=10,94, \mathrm{TA}=1.1$ and 1-2 years of practice experience $(\mathrm{MO}=1,44, \mathrm{TA}=1,4)$. The intervention program had 10 weeks duration, with 3 practices per week. For the needs of this study, an internet site (www.minivolley.gr) was used which had been created for this purpose. The athletes entered the positioning in their free time. The location contained sketches, 3D animations, videos with practice exercises, and presentations for the teaching and learning of the three basic Volleyball skills and their regulations. At the tip of the intervention, the comfort of attending the electronic courses was evaluated. The appropriateness of digital educational material according to the perceived view of the learners was evaluated using a part of the questionnaire of (Sun et al., 2008) while the intrinsic motivation of athletes was used the Intrinsic Motivation Inventory (Mc Auely et al., 1989). The results showed a statistically significant improvement in all of the variables of both questionnaires.
\end{abstract}

Keywords: multimedia, perceived view of use, motivation, volleyball skills

\section{Introduction}

Until recent years, through what we call traditional teaching, learning opportunities came from using and reading books or attending teacher lectures while taking notes (Chittaro

i Correspondence: email elzet@phyed.duth.gr 
\& Ranon, 2007), which is insufficient within the field of learning for our days. The traditional way of teaching-learning concerns the time of the lesson, where the students sit silently within the classroom and this can be done as some people just should answer questions or say the lesson. At the tip of the lesson, the teacher will take the written or oral test to look at the students.

Technology today has rapid developments in all areas, playing a vital role in people's daily lives. It has entered education at an identical pace. Because of the rapid development of technology in both society and education, teachers face challenges to fulfill the requirements of students, who are already very accustomed to it as they use it in their daily lives (Krause et al., 2017). The mixing of recent technologies discloses new possibilities for teaching and learning and provides students with the chance to extend their enthusiasm and enhance their learning outcomes (Stanojević \& Ranđelović, 2018).

The prospect of using online multimedia applications that incorporate $3 \mathrm{D}$ animation for learning purposes has aroused the growing interest of the academic community and has therefore created significant research work. Especially within the field of physical education, the academic perspective for 3D animations depicting motifs of sports activities has attracted the eye of researchers. Insight of the above, it seems appropriate to form a Lesson Management System (LSM) supported the multimedia applications so as to support the academic process of kids aged 10-12 years, as far as the movement patterns, rules, and process of mini volleyball are concerned. Presenting a unique fun and graphic way of teaching would support the new data so that it could be achieved better learning. Students should gain relevant experience and practice during their studies.

This suggests that the foremost important consider the sphere of learning is the activation of students. To realize this, students must become conversant in the thought of collaboration and be able to learn the way to cope with problems together and participate actively within the environment within which they're called to be active (Hmelo-Silver, 2004). The results of the new approaches are that students remember over 10 percent of what they were taught. Something that happened in traditional teaching. This may flow from the additional activity of the students during the educational process (Li, 2015). One in all the strategies that favor learning is the visualization of knowledge (Taylor, 2002). The image attracts attention and interest and makes the lesson more attractive. A straightforward text repels the student since his way of life is filled with images (Bosniadou, 2006; Giakoumatou, 2003). Particularly, mag illustration could be a universally understood language that evokes the senses, transforms the abstract into the concrete, and adds slightly of adventure, agony, and infrequently mystery to the reader's imagination (Burton, 1955). Multimedia instruction has been tagged with many advantages, including the capacity to provide high-quality images, (Vichitvejpaisal, Sitthikongsak, Preechakoon et al. 2001) active learner involvement, (Farrow, \& Sims, 1987), and flexibility by allowing students to learn at their own pace (Rouse, 2000).

Learning skills through multimedia is predicated on the idea of dynamic developmental systems and children's learning skills. In keeping with this theory, movement isn't only produced by the Central Nervous System (CNS) but is created by 
continual interaction between skill, person, and environment (Tzetzis \& Lola, 2015). More simply, the forthcoming learning is an interaction between the environment and also the cooperation of the inner processes of the musculoskeletal, nervous, and sensory systems. The speculation of social learning, proposed by Albert Bandura (1977), emphasizes the importance of observing, modeling, and imitating the behaviors, attitudes, and emotional reactions of others. In keeping with Bandura's theory, human learning and behavior also are influenced by cognitive, environmental, and peripheral factors. The four steps in Bandura's Social Learning Theory are attention, retention, reproduction, and motivation, which might be activated using multimedia.

From a pedagogical point of view, Paivio's theory of dual coding (Clark \& Paivio, 1991) holds a supportive position in line with which individuals store and decode information in two connected memory systems, language (verbal information) and pictures (non-verbal). That is, they encode information in an exceedingly double way, that the image is more practical in learning, when in the middle of verbal text and contrariwise. Supported the above, ways are often explored for the p.c. to contribute to effective learning with strategies supported teaching with simultaneous presentation of narration and animation (Solomonidou, 2006). Thus, the teacher's purpose is to form a vigorous learning environment. Since the education of motor skills is finished with the utilization of three senses (hearing, sight, kinesthetic) the multimedia directly covers the two while the exercise/practice will cover the third. The effectiveness of existing traditional education curricula in educational institutions remains low (Drachuk et al., 2018; Furman et al., 2018). The study of the fashionable literature has shown that the system of school physical education and novice athletes requires innovative changes, especially within the methodology of building learning. One of the most effective ways to unravel this problem is considering the deliberate use of recent tools and methods of studying courses supported by information and communication technologies. Recent types of research suggest could be employed in education and sports. They create the lesson more attractive and enjoyable.

Furthermore, multimedia learning shows an interesting side effect: due to high motivation and interest, learners engage more in multimedia learning (Baker, Hale, \& Gifford, 2004; Hasebrook, 1997) and except for computer training programs, all other media increase the learning time. Overall, current evidence shows that multimedia learning has the power to enhance learners' effectiveness, efficiency and attitude compared to traditional learning if the various constraints are taken into account, specific constellations of conditions are present and a fit of the learning system, learners' characteristics, teachers' characteristics, and learning content is ensured. However, there is a great number of studies finding no or only little advantage of multimedia learning comparing with traditional learning (Bernard, Abrami, Borokhovski, Wade, Womey, Wallet, Fiset, \& Huang, 2004; Russell, 1999). There is not so clear yet if multimedia learning is better than traditional learning (Vernadakis, Zetou, Avgerinos, Giannousi, \& Kioumourtzoglou, 2006) in learning volleyball skills, or long jump skill (Vernadakis, Avgerinos, Zetou, Giannousi \& Kioumourtzoglou Zetou, 2006). Vernadakis, Zetou, Antoniou, and Kioumourtzoglou (2004) also reported that multimedia is a functional 
method in teaching the skill of basketball shooting to middle school students, aged 12 14 years old and is as effective as the traditional teaching method. The results of this study showed that there were no significant differences between the multimedia and traditional teaching groups with regards to the knowledge and skill test.

As many researchers suggest, multimedia may be a modern learning tool within the classroom, and recently it's been utilized in both education and sports. The effectiveness of the utilization of multimedia relies on the idea of knowledge visualization that helps the student to store this information in his memory for later retrieval. It makes the lesson more attractive/enjoyable, so students/athletes are motivated to learn. Within PE and in sports multimedia could be a very useful auxiliary tool, since the most goal of learning is the correct execution and application of skills.

Therefore, the aim of this study was to explore multimedia usability and the importance of using them in developing the motivation of participants in learning sports skills.

\section{Material and Methods}

\subsection{Participants and Procedures}

The participants were 63 beginner volleyball female athletes, aged 10-12 years $(\mathrm{MO}=$ $10,94, \mathrm{TA}=1.1$ and $1-2$ years of practice experience $(\mathrm{MO}=1,44, \mathrm{TA}=1,4)$. The intervention program had 10 weeks duration, with 3 practices per week.

\subsection{Design and Instruments}

For the wants on this study, an internet site (www.minivolley.gr) was used which had been created for this purpose. The athletes entered the positioning in their free time. The location contained sketches, 3D animations, videos with practice exercises, and presentations for the teaching and learning of the three basic volleyball skills and their regulations.

In the end of the intervention, the comfort of attending the electronic courses was evaluated. For the appropriateness of digital educational material according to the perceived view of the participants, a part of the questionnaire (Sun, Tsai, Finger, Chen, \& Yeh, 2008) which had applied in the Greek population by (Syropoulou, Amprasi, Karageorgopoulou, \& Giannousi 2018) was used. This part of the questionnaire consisted of 3 factors (e-Learning course quality, technology quality, perceived ease of use) and was tested for its validity and reliability.

At the identical time, the Intrinsic Motivation Inventory (IMI) of McAuely, Dancan and Tammen, (1989) in its Greek version (Goudas \& Papacharisis, 1995) was used to evaluate the motivation of the young athletes. This is often geared towards athletes aged 10 and over, with 20 questions, and consists of 4 factors a) pleasure-interest b) effortimportance c) perceived ability and d) pressure-intensity. In both questionnaires used the answers were given on a five-point Likert scale, from $1=$ strongly disagree to $5=$ strongly agree. 


\subsection{Statistical Analysis}

The IBM SPSS (version 24) was used for statistical analyses. Both descriptive statistics and inductive statistics were used for data analysis. The internal consistency of the measurement scales was examined with the McDonald ohm factor (McDonald, 1985), which is considered an indicator of the generalizability of the results and an indicator of the further validity of the conceptual construction. The inductive statistical test used was the t-test of a sample to examine whether the mean value of the variable under consideration differs statistically significantly from the mean of the response scale.

\section{Results}

From the evaluation of the average scores of the variables of the e-course evaluation questionnaire, it was observed that the degree of "e-Learning course quality" of the participants was high, with the average value of the score of the respective dimension being equal to 3.88 (T.A. = .69). The degree of "technology" was at high levels, with the average score of the respective dimension being equal to 4.04 (T.A. $=.53$ ). Finally, the degree of "perceived ease of use" of the participants was at moderate to high levels with the average score of the respective dimension being equal to 3.33 (T.A. = .64) (Table 1 ).

Table 1: Descriptive Statistics and Internal Coherence of the Online Course Evaluation Questionnaire

\begin{tabular}{lcc} 
& M (SD) & McDonald's $\omega$ \\
\hline E-Learning course quality & $3.88(.69)$ & .50 \\
Technology quality & $4.04(.53)$ & .63 \\
Perceived ease of use & $3.33(.64)$ & .73
\end{tabular}

Table 2 shows the results of the t-test of a sample to check whether the mean value of each variable (e-Learning course quality, technology, and perceived ease of use) differs statistically significantly from the mean of the response scale, which is three (3). This difference was statistically significant at the significance level of $1 \%$, as confirmed by the test results ( $p$-value $<0.01$ ). Apart from being statistically significant, the differences were also substantial as shown by Cohen's d effect size index.

Table 2: Results of One-Sample T-Test of the Variables of the Electronic Course Evaluation Questionnaire

\begin{tabular}{lcccc} 
& $\boldsymbol{t}$ & $\boldsymbol{d f}$ & $\mathbf{p}$ & Effect size \\
\hline E-Learning course quality & 10.06 & 62.0 & $<.001$ & 1.267 \\
Technology quality & 15.40 & 62.0 & $<.001$ & 1.940 \\
Perceived ease of use & 4.05 & 62.0 & $<.001$ & 0.510
\end{tabular}

From the evaluation of the average scores of the variables of the internal motivation questionnaire, it was observed that the degree of interest of the participants was the highest, with the average score of the respective dimension being equal to 4.21 (T.A. $=$ 
.44). In contrast, the degree of stress/pressure is the lowest with the average score of the respective dimension being equal to 2.96 (T.A. $=.44)$ (Table 3).

Table 3: Descriptive Statistics and Internal Coherence of the Internal Motivation Questionnaire

\begin{tabular}{lcc} 
& M (SD) & McDonald's $\omega$ \\
\hline Pleasure-interest & $4.21(.44)$ & .58 \\
Effort-importance & $3.31(.37)$ & .57 \\
Perceived ability & $3.61(.44)$ & .57 \\
Pressure-intensity & $2.96(.44)$ & .57
\end{tabular}

Table 4 shows the results of a sample t-test to examine the extent to which the mean value of the four variables (interest/pleasure, effort/significance, and perceived ability) differs statistically significantly from its mean value. The corresponding scale corresponds to three (3). It was found that the average value of the three variables - interest/pleasure, effort/importance, and perceived ability differs from the value under consideration $\mu 0=$ 3.00. This difference was statistically significant at the significance level of $1 \%$, as confirmed by the test results ( $\mathrm{p}$-value $<0.01$ ). Finally, the difference was not statistically significant for the "stress/pressure" dimension.

Table 4: Results of One Sample T-Test of the Internal Motivation Questionnaire

\begin{tabular}{lcccc} 
& $\boldsymbol{t}$ & $\boldsymbol{d f}$ & $\mathbf{p}$ & Effect size \\
\hline Pleasure-interest & 20.08 & 53 & $<.001$ & 2.73 \\
Effort-importance & 6.08 & 53 & $<.001$ & .83 \\
Perceived ability & 10.12 & 53 & $<.001$ & 1.38 \\
Pressure-intensity & -.68 & 53 & .499 & -.09
\end{tabular}

\section{Discussion}

The aim of this study was to explore multimedia usability and the importance of using them in developing the motivation of participants in learning sports skills. The usability of educational software is a vital criterion for its quality and selection to be wont to support learning. Software usability in line with ISO $9241-11$ is defined as "the degree to which a system may be utilized by specific users to attain specific objectives under defined conditions of use efficiently, effectiveness, providing subjective satisfaction to its users". The rapid development of technology, the power to make a more attractive, friendly, and "perfected" teaching approach through it, raises the question of its contribution to the academic process and particularly to the training of motor skills. The likelihood of using the net at an identical time shouldn't be overlooked. The evolution of the latest technologies, together with the familiarity of youngsters in them, creates a replacement opportunity within the learning process. Multimedia applications are attractive to young people. The website utilized in this study by the athletes and requested to be evaluated as a web course (www.minivolley.gr) contained sketches, 3D animations, videos with practice exercises, and presentations for the teaching and learning of the three basic volleyball skills and their regulations. Learning physical 
activities, like sports and games, costs money and time. With repetition, one can reach perfection, but this presupposes that the incorrect actions are identified and avoided. The foremost accessible means of complementary learning are books and videos.

In this respect, the approach followed in the present study is consistent with Dalgarno et al., (2010), who correctly assess that they unfortunately only have twodimensional images, and readers or viewers who want to observe how it is performed a selected move from another angle cannot do. 3D learning environments bring together features that facilitate learning to a greater extent than their $2 \mathrm{D}$ counterparts. In the present study and the evaluation of the e-course, which came about, the degree of "digital learning" of the participants was high. All three variables differ statistically significantly at the importance level of $1 \%$, as confirmed by the test results ( $p$-value $<0.01$ ). Other than being statistically significant, the differences also are substantial. These results are almost like Xu Lifeng (2016) evaluated the impact of multimedia teaching using questionnaires. His results show that over $55 \%$ of education students were satisfied with teaching using multimedia. The nature of multimedia makes them particularly attractive in educating kids because interactivity encourages children to play an active role within the learning process. There are high expectations that digital technology will optimize student learning in schools and this can be reflected within the increase in educational policies and new curricula.

As far as internal regulation is the internally motivated behavior that reflects fun, pleasure, and therefore the need for autonomy, competence, and ability. E.g. when a student participates in the lesson because he or she has fun.

The logic of the used questionnaire is predicated on the very fact that individuals who participate in an activity thanks to internal motivations should experience similar emotional and cognitive states and at the identical time display relevant behaviors. So, to the extent that individuals report through the questionnaire: a) that they enjoy and have fun with their participation within the activity b) that activity arouses interest c) that they make an effort $d$ ) that the activity is very important to them e) that they feel able to cope the difficulties of the activity and $\mathrm{f}$ ) don't feel pressure or tension from their participation we are able to conclude the existence of internal motivation from the participation.

The results of the current study using the Intrinsic Motivation Inventory prove the truth in this regard because the assessment of the internal motivation stated by the athletes was related to the use of the website created to be used to improve the learning of the three basic volleyball skills. Three out of 4 variables (interest/pleasure, effort/significance, perceived ability), differ statistically significantly. This difference is statistically significant at the importance level of $1 \%$, as confirmed by the test results. This observation shows that the level of interest of the participants was high. On the contrary, at the same time, the voltage/pressure variable was the lowest and not statistically significant. This means that the impact of the site was positive if it was further combined with the students' already stated opinion about the usability of the site. 


\section{Conclusion/recommendations}

As conclusions, it seems that the pedagogical use of technology can provide opportunities for individualized instruction, communication, enjoyment, and motivation when used with attention to promoting movement literacy and improving the standard of PE and sport skill teaching. In order to be achieved all these the foremost effective way is thru multimedia computer-assisted instruction. Therefore, it is suggested to P.E. teachers and coaches to use multimedia applications in the weekly training process, so as to have motivated athletes / students for competing in practice and to learn skills correctly.

Consequences for future research in conclusion, multimedia programs can be utilized to enhance the effectiveness of teaching strategies or techniques in physical education classes and sports. Multimedia can also be used for the teaching of the cognitive aspects of sports such as rules and scoring procedures, and to allow teachers to have more time to spend with students' motor skills. Multimedia programs have been generally successful especially when it has been used in connection with regular classroom instruction (Vernadakis et al., 2004).

However, these conclusions are limited for students aged 8-12 years old. More studies should be conducted to investigate the effect of multimedia in different ages and for various sports activities. Also, it is critical to continue researching into how students learn in different technological environments since the researchers have only begun to explore the uses and practicality of multimedia.

The consequence for future practice Education today is experiencing a variety of problems such as budget cuts and large class sizes, and teachers are being seriously affected by these problems. Teachers must find new and better ways to facilitate the learning of students. For example, physical education or sports classes can be divided, one group working with software programs such as multimedia instruction, while the other group can be at the gymnasium or at a teaching station, learning the motor skills involved in the sport. Teachers would have more engaged time with each student because the group would be small. Therefore, physical education teachers and coaches have to take full advantage of the new technology such as multimedia programs. It is of upmost importance to educate teachers and provide them with opportunities to build new teaching strategies which incorporate the use of multimedia and advanced technologies.

\section{Conflict of Interest Statement}

The authors declare no conflicts of interests.

\section{About the Authors}

Kioumourtzoglou, J., MSc, in 3D animation, PhD student of School of Physical Education and Sport Sciences, Democritus University of Thrace, Greece.

Zetou, E., Professor in Motor learning in Volleyball, School of Physical Education and Sport Sciences, Democritus University of Thrace, Greece. 
Giannousi, M., PhD, Teaching Technology Applications in Physical Education, School of Physical Education and Sport Sciences, Democritus University of Thrace, Greece.

Antoniou, P., Professor in New Technologies in Physical Education and Sports, School of Physical Education and Sport Sciences, Democritus University of Thrace, Greece.

Michalopoulou, M., Professor in Acquisition of Skills in Physical Activity and Sports, School of Physical Education and Sport Sciences, Democritus University of Thrace, Greece.

\section{References}

Baker W., Hale T., Gifford B. R. (2004). From theory to implementation. The mediated learning approach to computer-mediated instruction, learning and assessment. http://www.educause.edu/pub/er/review/reviewArticles/32542.html

Bandura A. (1977). Social learning theory. Englewood Cliffs, NJ: Prentice-Hall

Bernard R. M., Abrami P. C., Borokhovski E., Wade A., Womey L., Wallet P. A., Fiset M., Huang B. (2004). How does distance education compare with classroom instruction? A meta-analysis of the empirical literature. Review of Educational Research, 74(3), pp. 379-439.

Bosniadou S. (2006). Children, Schools and Computers Athens Gutenberg, pp. 31-56

Burton D. L. (1955). Comic Books: A Teacher's Analysis. The Elementary School Journal, Vol. 56, No2, pp. 73-75.

Clark J. M., Paivio A. (1991). Dual coding theory and education. Educational Psychology Review, 3(3), 149-210. https://doi.org/10.1007/BF01320076

Chittaro L., Ranon R. (2007). Web3D technologies in learning, education and training: Motivations, issues, opportunities. Computers \& Education

Dalgarno, Barney Lee, Mark J. W. (2010). What are the learning affordances of 3-d virtual environments? British Journal of Educational Technology, V 41, No1, pp. 10-32 (23)

Drachuk S., Bohuslavska V., Pityn M., Furman Y., Kostiukevych V., Gavrylova N., Salnykova S., Didyk T. (2018). Energy supply capacity when using different exercise modes for young 17-19- year-old men. Journal of Physical Education and Sport, 18 (1), Art. 33, pp. 246-254. DOI:10.7752/jpes.2018.0103

Farrow M, Sims R. (1987). Computer-assisted learning in occupational therapy. Austr Occup Ther J., 34:53-58. [Google Scholar]

Furman Yu. M., Miroshnichenko V. M., Brezdeniuk O. Yu., Furman T. Yu. (2018). Estimation of aerobic and anaerobic productivity of an organism of youth aged 1719 years old of Podilsk region. Pedagogics, psychology, medical-biological problems of physical training and sports, 22 (3), 136-141. DOI:10.15561/18189172.2018.0304

Giakoumatou T. (2003). New Technologies Meet the Greek School Association of Philologists of Aigialeia and Kalavrita "Dokei moi" Aigio, vol. 1. www.e-yliko.gr/epimorf/fil/DOKEIMOI.pdf. 
Goudas M., Papacharisis V. (1995). Laboratory of Exercise and Quality of Life, Department of Physical Education and Sports, University of Thessaly, Greece.

Hasebrook J. P. (1997). Wem nützt Multimedia - und warum? - Lebenslanges Lernen mit Multimedia Whom does multimedia support - and why? - Life-long learning with multimedia. Multi-Media-Mania. Refl exionen zu Aspekten neuer Medien, ed. R. Pfammatter, UVK Medien: Konstanz, pp. 101-124, 1997.

Hmelo-Silver C. E. (2004). Problem-Based Learning: What and How Do Students Learn? Educational Psychology Review 16(3):235-266 DOI: 10.1023/B:EDPR.0000034022.16470.f3

Krause J. M., Franks H., Lynch B. (2017). Current technology trends and issues among health and physical education professionals. The Physical Educator, 74(1), 164-180

Li J. (2015). Students forget $95 \%$ of what they learn in high school after 3 days. Here's how to help them study. https://blog.mytuition.nz/high-school/students-forgeteverything-heres-how-to-help-them-stud

Mc Auely E., Dancan T., Tammen V. V. (1989). Psychometric properties of the Intrinsic Motivation Inventory in a competitive sport setting: a confirmatory factor analysis. Research Quarterly Exercise and Sport, 60(1), 48-58. DOI: $\underline{10.1080 / 02701367.1989 .10607413}$

McDonald R. P. (1985). Factor analysis and related methods. Hillsdale, NJ: Erlbaum Russell T. L. (1999). The no significant difference phenomenon. North Carolina State University.

Rouse D. P. (2000). The effectiveness of computer-assisted instruction in teaching nursing students about congenital heart disease. Comput Nurs.18:282287. [PubMed] [Google Scholar]

Stanojević Lj., Ranđelović, M. (2018). The effect of web-based classroom response system on students learning outcomes: results from programming course, Megatrend Review, 15 (2), 213-232.

Solomonidou, Ch. (2006). New trends in educational technology. Constructivism and modern learning environments. Athens: Metaichmio Publications

Sun, P. C., Tsai R. J., Finger G., Chen Y. Y., Yeh D. (2008). What drives a successful eLearning? An empirical investigation of the critical factors influencing learner satisfaction. Computers \& Education, 50(4):1183-1202.

Syropoulou A., Amprasi E., Karageorgopoulou M., \& Giannousi M. (2018). Children's attitudes towards immersive virtual reality exergames: Validity and reliability of a psychometric questionnaire. PANR Journal, 29 November. https://www.panr.com.cy/?p=1707.

Taylor, E. S. (2002). Health Psychology with Power Web McGraw-Hill Humanities /Social Sciences/Langua (January 1, 1774) ASIN: B01JXNIYKC

Tzetzis G., Lola, A. (2015). The Fitts and Posner Model (1967) (Chapter 3), Motor Learning and Development (p. 43). Zografou: Creative Commons

Vernadakis N., Zetou E., Avgerinos A., Giannousi M., Kioumourtzoglou E. (2006). The effects of multimedia computer-assisted instruction on middle school students' 
volleyball performance. The engineering of sport 6, Volume 3: Developments for innovation, ed. E.F. Moritz \& S. Haake, Springer-Verlag: New York, pp. 221-226.

Vernadakis N., Zetou E., Antoniou P., Kioumourtzoglou E. (2004). Comparison of three different instructional methods on teaching the skill of shooting in basketball. Journal of Human Movement Studies, 46, pp. 421-440.

Vernadakis N., Avgerinos A., Zetou E., Giannousi M., \& Kioumourtzoglou Zetou (2002). The effectiveness of computer-assisted instruction on teaching the skill of setting in volleyball. Journal of Human Movement Studies, 43, pp. 151-164.

Vichitvejpaisal P., Sitthikongsak S., Preechakoon B., et al. (2001). Does computer-assisted instruction really help to improve the learning process? Med Educ, 35:983989. [PubMed] [Google Scholar]

$\mathrm{Xu}$, Lifeng (2016). Study on Multimedia Teaching and the Reform of College Physical Education: Evaluation of Teaching Effect International Journal of Security and Its Applications Vol. 10, No. 2 pp.255-266 http://dx.doi.org/10.14257/ijsia.2016.10.2.23 
Kioumourtzoglou, J.; Zetou E.; Giannousi M.; Antoniou, P.; Michalopoulou, M.

MULTIMEDIA AS AN INCENTIVE FOR INTERNAL MOTIVATION AND USE OF COMPUTERS IN SPORTS

Creative Commons licensing terms

Authors will retain the copyright of their published articles agreeing that a Creative Commons Attribution 4.0 International License (CC BY 4.0) terms will be applied to their work. Under the terms of this license, no permission is required from the author(s) or publisher for members of the community to copy, distribute, transmit or adapt the article content, providing a proper, prominent and unambiguous attribution to the authors in a manner that makes clear that the materials are being reused under permission of a Creative Commons License. Views, opinions and conclusions expressed in this research article are views, opinions and conclusions of the author(s). Open Access Publishing Group and European Journal of Physical Education and Sport Science shall not be responsible or answerable for any loss, damage or liability caused in relation to/arising out of conflict of interests, copyright violations and inappropriate or inaccurate use of any kind content related or integrated on the research work. All the published works are meeting the Open Access Publishing requirements and can be freely accessed, shared, modified, distributed and used in educational, commercial and non-commercial purposes under a Creative Commons attribution 4.0 International License (CC BY 4.0). 